\title{
Predictors of Poor Postoperative Outcomes in Pediatric Surgery Patients in Rural Ghana
}

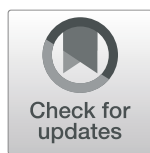

Sarah Peiffer ${ }^{1 *}\left(\mathbb{D}\right.$, Anna E. Ssentongo ${ }^{1}$, Laura Keeney ${ }^{1}$, Forster Amponsah-Manu², Richard Yeboako², Richard Ofosu-Akromahn², Temitope Ebenezer Arkorful ${ }^{2}$, Eric Agyemang ${ }^{2}$, Anthony Tsai ${ }^{1}$, John $\mathrm{Oh}^{1}$ and Paddy Ssentongo ${ }^{1}$

\begin{abstract}
Background/Purpose: Perioperative complications cause significant pediatric morbidity and mortality in low- and lower middle -income countries. This study investigates factors associated with prolonged length of stay, 90-day readmission and in-hospital mortality among pediatric patients at Eastern Regional Hospital (ERH) in Ghana.

Methods: This is a retrospective review of perioperative morbidity and mortality in children $<18$ years at ERH in Koforidua, Ghana. All pediatric surgeries performed between January 2015 and December 2017 were included in this study. Univariate analysis was performed using Pearson's chi-square tests or Fisher's exact tests. Variables that were significant on univariate analysis were included in multivariable logistic regression models adjusted for age and gender.

Results: We analyzed 468 patients $<18$ years of age with a median length of stay (LOS) of 3 days. The 90-day readmission and in-hospital mortality rates were 138 and 17 per 1000 patients, respectively. The most common procedures were herniorrhaphy (19\%) and appendectomy (15\%). Gastrointestinal surgery, surgical trauma, surgical infection and lack of insurance were significantly associated with prolonged LOS. Young age and female gender were significantly associated with in-hospital mortality. Malaria was significantly associated with 90-day readmission.

Conclusions: Malaria infection is a significant risk factor for readmission, which should be investigated and treated in pediatric surgical patients in rural Ghana. Ensuring that all patients have insurance may result in shorter hospital stays. Provision of laparoscopic equipment may reduce hospital stays for patients undergoing gastrointestinal surgery. Expansion of the surgical work force, particularly pediatric surgeons, could improve perioperative survival in the very young population.
\end{abstract}

Level of Evidence: Retrospective comparative study.

Keywords: Pediatric surgery, Outcomes, Morbidity, Mortality, Africa, Global health

\footnotetext{
*Correspondence: speiffer@pennstatehealth.psu.edu

'Penn State University College of Medicine, 500 University Drive, Hershey, PA

17033, USA

Full list of author information is available at the end of the article
}

(c) The Author(s). 2020 Open Access This article is licensed under a Creative Commons Attribution 4.0 International License, which permits use, sharing, adaptation, distribution and reproduction in any medium or format, as long as you give appropriate credit to the original author(s) and the source, provide a link to the Creative Commons licence, and indicate if changes were made. The images or other third party material in this article are included in the article's Creative Commons licence, unless indicated otherwise in a credit line to the material. If material is not included in the article's Creative Commons licence and your intended use is not permitted by statutory regulation or exceeds the permitted use, you will need to obtain permission directly from the copyright holder. To view a copy of this licence, visit http://creativecommons.org/licenses/by/4.0/ The Creative Commons Public Domain Dedication waiver (http://creativecommons.org/publicdomain/zero/1.0/) applies to the data made available in this article, unless otherwise stated in a credit line to the data. 


\section{Background}

Despite overall gains in global health, the burden of surgical diseases and complications in low- and lower middle- income countries (LMICs) remains high. In 2018, one in five surgical patients in LMICs had poor postoperative outcomes, such as surgical site infection (SSI), wound complication, or death [1]. An estimated 5 billion people do not have timely access to safe, affordable surgery [2]. The most substantial unmet need for surgical care is found in sub-Saharan Africa [2], in-which $43 \%$ of the population is under 15 years old [3]. The burden of surgical disease is high within the pediatric population [4], accounting for $6-12 \%$ of pediatric admissions in sub-Saharan Africa [5] with an overall mortality rate of $12 \%$ [6]. Unmet pediatric surgical need is a significant contributor to death and disability [5].

Pediatric surgery presents unique challenges which make it distinct from adult general surgery. Children present with different surgical pathologies, respond differently to anesthesia, and have special perioperative needs associated with high perioperative mortality [5, 7]. The vast majority of research on perioperative morbidity and mortality is from developed countries [7-12], and the number of studies that have looked at the influence of medical comorbidities unique to sub-Saharan Africa are limited [13-16]. Pediatric surgery in sub-Saharan Africa is disadvantaged by limited resources, high numbers of sick patients relative to the number of providers, and high frequency of delayed presentations with advanced pathologies [13]. Lack of finances and transportation are significant barriers to care, and cultural preference for traditional medicines and home remedies may significantly delay patient presentations [4, 17].

Previous studies have found that risk factors for perioperative mortality in sub-Saharan Africa include neonatal age group, delayed presentation, emergency surgery, high American Society of Anesthesiologists (ASA) status, and multiple operative procedures $[6,18,19]$. Other studies have suggested that increased postoperative complication rates occur with poor nutrition [20] and medical comorbidities such as HIV infection [15]. However, factors associated with pediatric surgical mortality and poor postoperative outcomes in sub-Saharan Africa may vary greatly across the continent. Therefore, this study aims to investigate factors associated with prolonged length of stay, readmission within 90 days and in-hospital mortality among pediatric patients at the Eastern Regional Hospital in Ghana.

\section{Methods}

\section{Study design}

A retrospective review was performed on the medical records of all patients $<18$ years old who were admitted to the surgical ward from January 2015 through December
2017 at the Eastern Regional Hospital (ERH) in Koforidua, Ghana. ERH is a referral center for 26 district hospitals in the Eastern Region and has a surgical volume of over 2500 cases per year. Like many other regional and district hospitals in Ghana, ERH has no pediatric surgical specialists so all pediatric cases are operated on by general surgeons. ERH serves a catchment area with a population of approximately 3 million, more than $40 \%$ of which are children. A secondary analysis was conducted to examine possible associations between gender, insurance status, surgical procedure, malaria, anemia, white blood cell count (WBC), congenital or acquired conditions, type of procedure, length of stay, readmission and mortality. The study protocol was reviewed and approved by the internal review board of Penn State Milton S. Hershey Medical Center and by the ethical review board at ERH. In addition, this study was evaluated and approved by ERH for cultural appropriateness.

\section{Study population}

The study subjects were identified through billing records using patient identification numbers recorded in the ERH administration and management system. All patients $<18$ years old who had surgery at ERH from January 1, 2015 to December 31, 2017 were included in this study. Patients were excluded from the analysis if they were admitted to the surgical ward but did not undergo a surgical procedure. The authors acknowledge that in Ghana only children $<12$ years old are considered pediatric patients, however the authors elected to include patients up to age 17 in order to maximize the sample size and to allow for comparison to studies conducted in countries with broader definitions of pediatric patients.

\section{Review of patient records}

From the electronic medical records, information for each study subject was obtained including age, gender, insurance status, date of admission, date of surgery, date of discharge, length of stay (LOS), diagnosis, type of procedure, date of death, preoperative hemoglobin, preoperative WBC count, preoperative serum glucose, HIV, malaria, date of readmission, reason for readmission, and surgical site infection. For each patient, the diagnosis was categorized as congenital or acquired. Surgical procedures were classified as gastrointestinal, genitourinary, injury, neoplasm, surgical infection (management of an infection, such as surgery for infection source control) or miscellaneous. Prolonged LOS in this study was defined as greater than the median LOS, which was 3 days, thus prolonged LOS was defined as an admission lasting greater than or equal to 4 days. For the purposes of data analysis, anemia was defined as $\mathrm{Hgb}<12 \mathrm{mg} / \mathrm{dL}$, leukpenia as $\mathrm{WBC} \leq 4,500$ cells per $\mu \mathrm{L}$ and leukocytosis 
as $\mathrm{WBC} \geq 11,000$ cells per $\mu \mathrm{L}$. HIV and malaria tests were performed preoperatively during the initial surgical admission. Surgical site infections (SSI) included both superficial and deep incisional SSI as well as organ/space SSI identified either during the initial hospital admission, on outpatient follow-up visits or upon readmission.

\section{Statistical methods}

A 2-tailed 2-sample Student's t-test or Wilcoxon ranksum test was invoked to compare means or medians respectively for continuous outcomes variables between groups. We performed Pearson's chi-square tests or Fisher's exact tests for categorical variables. Values are expressed as the mean \pm standard deviation (SD) for normally distributed variables, as median and interquartile range for skewed distribution, and as counts and percentages for categorical variables. Values that were found to be significant on univariate analysis were included in multivariable logistic regression models using backward elimination method. All multivariable analyses were adjusted for age (which was centered by subtracting the mean age from raw age values) and gender. Point estimates are reported as odds ratios (OR) and $95 \%$ confidence intervals (CI) for each outcome (prolonged LOS, in-hospital mortality and 90-day readmission). The predictive models were cross-validated using leave-one outcross-validation methods [21]. To determine the discriminative power of the predictive models, the area under the receiver operating characteristic curve (AUC) was calculated [22]. Statistical analysis was performed using SAS, version 9.4; SAS Institute Inc and R software (R Core Team 2018). For all statistical tests, alpha level was set at 0.05 .

\section{Results}

During the study period, 595 pediatric patients presented to the surgical ward at ERH. A total of 127 patients were excluded due to lack of a surgical procedure. Analysis was performed on the remaining 468 patients,

Table 1 Descriptive Statistics: Demographics

\begin{tabular}{ll}
\hline Attribute & Cohort $(\boldsymbol{n}=\mathbf{4 6 8})$ \\
\hline Age in years, mean (SD) & $9.0(5.3)$ \\
Age Range & \\
$\leq 1$ yr, n (\%) & $17(3.6)$ \\
$2-3$ yrs, n (\%) & $79(17)$ \\
$4-8 y r s, ~ n(\%)$ & $138(29)$ \\
$9-13$ yrs, n (\%) & $105(22)$ \\
$14-17$ yrs, n (\%) & $129(28)$ \\
Gender & \\
Male, n (\%) & $422(90)$ \\
Female, n (\%) & $46(10)$ \\
\hline
\end{tabular}

Table 2 Descriptive Statistics: Clinical Attributes

\begin{tabular}{ll}
\hline Attribute & Cohort $(\boldsymbol{n}=\mathbf{4 6 8})$ \\
\hline Malaria, n (\%) & $25 / 207(12)$ \\
HIV, n (\%) & $0 / 130(0)$ \\
Insurance, n (\%) & $356(76)$ \\
Anemia, n (\%) & $127 / 194(65)$ \\
Leukopenia, n (\%) & $13 / 194(7)$ \\
Leukocytosis, n (\%) & $92 / 194(47)$ \\
Congenital vs Acquired & \\
Acquired, n (\%) & $420(90)$ \\
Congenital, n (\%) & $48(10)$ \\
Procedure Category & \\
Gastrointestinal, n (\%) & $274(59)$ \\
Genitourinary, n (\%) & $61(13)$ \\
Injury, n (\%) & $71(15)$ \\
Miscellaneous, n (\%) & $32(7)$ \\
Neoplasm, n (\%) & $19(4)$ \\
Surgical Infection, n (\%) & $11(2)$ \\
\hline
\end{tabular}

whose clinical attributes are summarized in Table 1 and Table 2. Their ages ranged from 3 days to 17 years with a mean age of 9.0 years (standard deviation (SD) \pm 5.3 years). Ninety percent of the patients in this study were male (Tables 1,2,3). Of note, all of the patients tested for HIV in this study were found to be HIV negative. The median length of stay was 3 days (IQR \pm 3 days). The 90-day readmission rate was 49 per 1000 patients. The in-hospital mortality rate was 17 per 1000 patients. The details of the children who died are provided in Table 4. Thirty-eight percent of the mortalities occurred in infants. Mortality in children older than 1 year was 9 per 1000 patients, which was much lower than in children less than or equal to 1 year, which was 235 per 1000 patients $(\mathrm{p}=<0.0001)$.

The pediatric surgical conditions were categorized by whether they were congenital (10\%) or acquired $(90 \%)$. The distribution of the types of pediatric surgical conditions are shown in Fig. 1. Gastrointestinal surgery was the most common category, with the leading surgical procedures being herniorrhaphy $(90 / 468,19 \%)$ and appendectomy (72/468, $15 \%$ ) (Fig. 2).

Summarized in Table 5 is the univariate analysis for the factors associated with prolonged $\operatorname{LOS} \geq 4$ days.

Table 3 Descriptive Statistics: Outcomes

\begin{tabular}{ll}
\hline Outcome & Cohort $(\boldsymbol{n}=\mathbf{4 6 8})$ \\
\hline Length of stay, median (IQR) & $3.0(3.0)$ \\
In-hospital Mortality, $\mathrm{n}(\%)$ & $8(2)$ \\
90-day Readmission, $\mathrm{n}(\%)$ & $23(5)$ \\
Surgical Site Infection, $\mathrm{n}(\%)$ & $2(0.4)$ \\
\hline
\end{tabular}


Table 4 Clinical Characteristics of Mortalities

\begin{tabular}{lllllll}
\hline Patient & Gender & Age & Insurance & Diagnosis & $\begin{array}{l}\text { Time from Admission } \\
\text { to Surgery (days) }\end{array}$ & $\begin{array}{l}\text { Time to Death } \\
\text { (Postop Day) }\end{array}$ \\
\hline 1 & 1 & $<1 \mathrm{mo}$ & Yes & $\begin{array}{l}\text { Bowel obstruction due to } \\
\text { congenital constricting bands } \\
\text { Esophageal atresia }\end{array}$ & 2 \\
2 & 1 & $<1 \mathrm{mo}$ & No & Bowel ischemia & 3 & 2 \\
3 & 1 & $<1 \mathrm{mo}$ & Yes & Intussusception & 4 & 3 \\
4 & 1 & $1-2 \mathrm{yrs}$ & Yes & Intussusception & 0 & 0 \\
5 & 2 & $3-5 \mathrm{yrs}$ & Yes & Intussusception & 3 \\
6 & 2 & $3-5 \mathrm{yrs}$ & Yes & Hepatic abscess & 3 & 32 \\
7 & 2 & $>5 \mathrm{yrs}$ & No & Typhoid perforation & 3 & 1 \\
8 & 2 & $>5 \mathrm{yrs}$ & Yes & & & \\
\hline
\end{tabular}

Older age, lack of insurance, anemia ( $\mathrm{Hgb}<12 \mathrm{mg} /$ $\mathrm{dl}$ ), leukocytosis ( $\geq 11,000$ leukocytes $/ \mu \mathrm{L}$ ), gastrointestinal surgeries and surgical management of infections were significantly associated with prolonged LOS. Similarly, summarized in Table 6 is the univariate analysis for predictors of in-hospital mortality. Younger age and female gender were significantly associated with in-hospital mortality. Similarly, summarized in Table 7 is the univariate analysis for predictors of 90-day readmission. Younger age and malaria infection were significantly associated with readmission within 90 days.

Summarized in Table 8 are the multivariable logistic regression results for each of the outcomes variables. Gastrointestinal surgery, surgical traumas, surgical infections and lack of insurance were found to be independent predictors of prolonged length of stay $\geq 4$ days. Male gender and older age were found to be inversely associated with in-hospital mortality. Finally, concurrent malaria infection was found to be an independent predictor of readmission within 90 days.

\section{Discussion}

This is the first study of perioperative outcomes in pediatric general surgery patients in rural Ghana. This study had several significant findings. First, that preoperative malaria infection is an actionable independent predictor of readmission in the pediatric surgical population in rural Ghana. Previous studies have shown that malaria is a leading cause of perioperative hyperpyrexia, increases the rate of surgical site infections, increases postoperative recovery and that surgery can cause reactivation malaria [23-28]. The burden of malaria infection in this region is highest in the pediatric population due to the immunological and behavioral drivers [29]. The underlying mechanism of readmission among patients with malaria is not fully understood. However, the pathophysiological changes caused by malaria infections, including excessive releases of cytokines and chemokines such as tumor necrosis factors and interleukin2 , could alter the healing process postoperatively [30]. Previous studies have suggested that surgery may weaken patients' immune systems, increasing their susceptibility to malaria and its complications or to other pathogens [16].

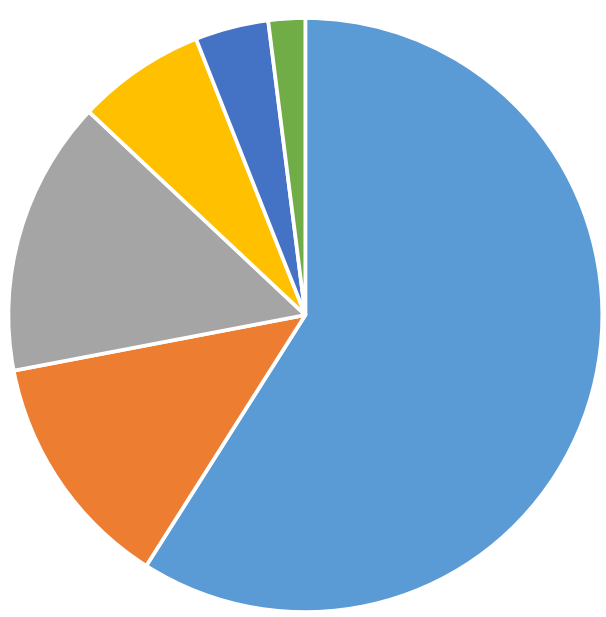

- Gastrointestinal

- Genitourinary

- Trauma

- Miscellaneous

- Neoplasm

- Infection Source Control

Fig. 1 Distribution of Types of Pediatric Surgical Admissions 


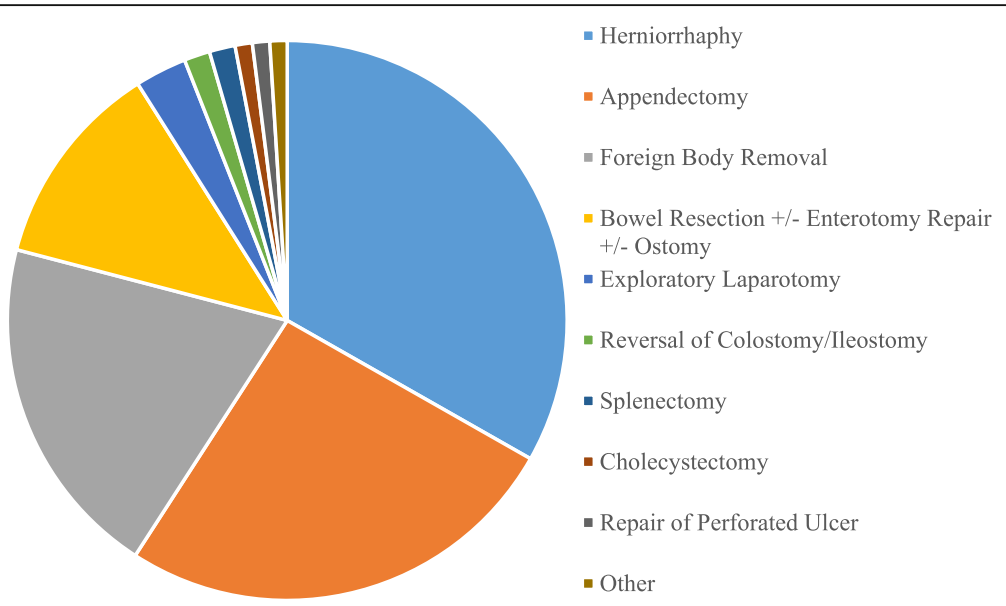

Fig. 2 Distribution of Types of Gastrointestinal Procedures

Table 5 Univariate Analysis for the Predictors of Prolonged Length of Stay Greater Than or Equal to 4 Days

\begin{tabular}{|c|c|c|c|c|}
\hline Attribute & Cohort $(n=468)$ & Length of Stay $<4$ days $(n=279)$ & Length of Stay $\geq 4$ days $(n=189)$ & $p$ Value \\
\hline Age years, mean (SD) & 468 & $8.5(5.2)$ & $9.6(5.4)$ & 0.0256 \\
\hline \multicolumn{5}{|l|}{ Gender } \\
\hline Male (\%) & $422(90)$ & $253(91)$ & $169(89)$ & \multirow[t]{2}{*}{0.6525} \\
\hline Female (\%) & $46(10)$ & $26(9)$ & $20(11)$ & \\
\hline \multicolumn{5}{|l|}{ Insured } \\
\hline No (\%) & $112(24)$ & $52(19)$ & $60(32)$ & \multirow[t]{2}{*}{0.0011} \\
\hline Yes (\%) & $356(76)$ & $227(81)$ & $129(68)$ & \\
\hline \multicolumn{5}{|l|}{ Malaria } \\
\hline No (\%) & $182(88)$ & $105(88)$ & $77(89)$ & \multirow[t]{2}{*}{0.8265} \\
\hline Yes (\%) & $25(12)$ & $15(12)$ & $10(11)$ & \\
\hline \multicolumn{5}{|l|}{ Anemia } \\
\hline No (\%) & $67(35)$ & $40(44)$ & $27(26)$ & \multirow[t]{2}{*}{0.0095} \\
\hline Yes (\%) & $127(65)$ & $51(56)$ & $76(84)$ & \\
\hline \multicolumn{5}{|l|}{ Leukopenia } \\
\hline No (\%) & $181(93)$ & $83(91)$ & $98(95)$ & \multirow[t]{2}{*}{0.2738} \\
\hline Yes (\%) & $13(7)$ & $8(9)$ & $5(5)$ & \\
\hline \multicolumn{5}{|l|}{ Leukocytosis } \\
\hline No (\%) & $102(53)$ & $56(62)$ & $46(45)$ & \multirow[t]{2}{*}{0.0188} \\
\hline Yes (\%) & $92(47)$ & $35(38)$ & $57(55)$ & \\
\hline \multicolumn{5}{|l|}{ Congenital vs Acquired } \\
\hline Acquired (\%) & $420(90)$ & $246(88)$ & $174(92)$ & \multirow[t]{2}{*}{0.1734} \\
\hline Congenital (\%) & $48(10)$ & $33(12)$ & $15(8)$ & \\
\hline \multicolumn{5}{|l|}{ Procedure Category } \\
\hline Gastrointestinal (\%) & $274(59)$ & $151(54)$ & $123(65)$ & \multirow[t]{6}{*}{0.0011} \\
\hline Genitourinary (\%) & $61(13)$ & $50(18)$ & $11(6)$ & \\
\hline Injury (\%) & $71(15)$ & $42(15)$ & $29(15)$ & \\
\hline Miscellaneous (\%) & $32(7)$ & $21(8)$ & $11(6)$ & \\
\hline Neoplasm (\%) & $19(4)$ & $12(4)$ & $7(4)$ & \\
\hline Surgical Infection (\%) & $11(2)$ & $3(1)$ & $8(4)$ & \\
\hline
\end{tabular}


Table 6 Univariate Analysis for the Predictors of Mortality

\begin{tabular}{|c|c|c|c|c|}
\hline Attribute & Cohort $(n=468)$ & Alive $(n=460)$ & Died $(n=8)$ & $p$ Value \\
\hline Age years. mean (SD) & 468 & $9.1(5.2)$ & $2.7(3.0)$ & 0.0004 \\
\hline \multicolumn{5}{|l|}{ Gender } \\
\hline Male (\%) & $422(90)$ & $418(91)$ & $4(50)$ & \multirow[t]{2}{*}{0.0043} \\
\hline Female (\%) & $46(10)$ & $42(9)$ & $4(50)$ & \\
\hline \multicolumn{5}{|l|}{ Insured } \\
\hline No (\%) & $112(24)$ & $109(24)$ & $3(38)$ & \multirow[t]{2}{*}{0.4042} \\
\hline Yes (\%) & $356(76)$ & $351(76)$ & $5(62)$ & \\
\hline \multicolumn{5}{|l|}{ Malaria } \\
\hline No (\%) & $182(88)$ & $179(88)$ & $3(100)$ & \multirow[t]{2}{*}{1.0000} \\
\hline Yes (\%) & $25(12)$ & $25(12)$ & $0(0)$ & \\
\hline \multicolumn{5}{|l|}{ Anemia } \\
\hline No (\%) & $67(35)$ & $65(34)$ & $2(40)$ & \multirow[t]{2}{*}{1.0000} \\
\hline Yes (\%) & $127(65)$ & $124(66)$ & $3(60)$ & \\
\hline \multicolumn{5}{|l|}{ Leukopenia } \\
\hline No (\%) & $181(93)$ & $177(94)$ & $4(80)$ & \multirow[t]{2}{*}{0.2957} \\
\hline Yes (\%) & $13(7)$ & $12(6)$ & $1(20)$ & \\
\hline \multicolumn{5}{|l|}{ Leukocytosis } \\
\hline No (\%) & $102(53)$ & $100(53)$ & $2(40)$ & \multirow[t]{2}{*}{0.6694} \\
\hline Yes (\%) & $92(47)$ & $89(47)$ & $3(60)$ & \\
\hline \multicolumn{5}{|l|}{ Congenital vs Acquired } \\
\hline Acquired (\%) & $420(90)$ & $414(90)$ & $6(75)$ & \multirow[t]{2}{*}{0.1936} \\
\hline Congenital (\%) & $48(10)$ & $46(10)$ & $2(25)$ & \\
\hline \multicolumn{5}{|l|}{ Procedure Category } \\
\hline Gastrointestinal (\%) & $274(59)$ & $266(58)$ & $8(100)$ & \multirow[t]{6}{*}{0.5798} \\
\hline Genitourinary (\%) & $61(13)$ & $61(13)$ & $0(0)$ & \\
\hline Injury (\%) & $71(15)$ & $71(15)$ & $0(0)$ & \\
\hline Miscellaneous (\%) & $32(7)$ & $32(7)$ & $0(0)$ & \\
\hline Neoplasm (\%) & $19(4)$ & $19(4)$ & $0(0)$ & \\
\hline Surgical Infection (\%) & $11(2)$ & $11(2)$ & $0(0)$ & \\
\hline
\end{tabular}

Treating malaria preoperatively can lead to potential cost savings and reductions in morbidity. At ERH, the average cost is \$16 USD per day of admission and an average length of stay of 4.3 days, the total direct cost of a hospital admission is approximately \$69 USD not including transportation or lost wages. According to 2016 World Bank calculations, Ghana's annual gross national income (GNI) per capita is $\$ 1840$ USD with a Gini coefficient of 0.435 [31]. In 2013, $21.7 \%$ of the population of the Eastern Region was living on less than 1,314 GHS (\$241 USD) per adult per year [32]. Therefore, a \$69 hospital admission would put a substantial financial burden on the family.

Consistent with previous studies, our study found an association between age and mortality [7, 11, 14, 19, 33, 34]. This may be the result of young children's immature immune systems [35] or complex congenital disease processes [34]. It is likely that social processes common throughout sub-Saharan Africa such as lack of neonatal intensive care unit, lack of pediatric surgical specialists or delay in presentation contributed as well [19]. Due to the lack of pediatric surgical specialist capacity, all pediatric surgeries at ERH are performed by the general surgeons. Therefore, it is possible that infants and neonates with surgical conditions in this region are less likely to be brought to this hospital for treatment or are more likely to be transferred to the national hospital with pediatric surgery specialists, contributing to low numbers of infants and neonates operated on at this facility. In addition, we cannot rule out the possibility that having general surgeons performing the cases rather than pediatric surgical specialists may have contributed to the correlation between young age and mortality. To our surprise, we also found an association between female gender and 
Table 7 Univariate Analysis for the Predictors of Readmission Within 90 Days

\begin{tabular}{|c|c|c|c|c|}
\hline Attribute & Cohort $(n=468)$ & Not readmitted $(n=445)$ & Readmitted $(n=23)$ & $p$ Value \\
\hline Age years. mean (SD) & 468 & $9.1(5.3)$ & $7.0(4.7)$ & 0.0494 \\
\hline \multicolumn{5}{|l|}{ Gender } \\
\hline Male (\%) & $422(90)$ & $399(90)$ & $23(100)$ & \multirow[t]{2}{*}{0.1511} \\
\hline Female (\%) & $46(10)$ & $46(10)$ & $0(0)$ & \\
\hline \multicolumn{5}{|l|}{ Insured } \\
\hline No (\%) & $112(24)$ & $109(24)$ & $3(13)$ & \multirow[t]{2}{*}{0.2094} \\
\hline Yes (\%) & $356(76)$ & $336(76)$ & $20(87)$ & \\
\hline \multicolumn{5}{|l|}{ Malaria } \\
\hline No (\%) & $182(88)$ & $170(90)$ & $12(67)$ & \multirow[t]{2}{*}{0.0116} \\
\hline Yes (\%) & $25(12)$ & $19(10)$ & $6(33)$ & \\
\hline \multicolumn{5}{|l|}{ Anemia } \\
\hline No (\%) & $67(35)$ & $64(35)$ & $3(25)$ & \multirow[t]{2}{*}{0.5492} \\
\hline Yes (\%) & $127(65)$ & $118(65)$ & $9(75)$ & \\
\hline \multicolumn{5}{|l|}{ Leukopenia } \\
\hline No (\%) & $181(93)$ & $169(93)$ & $12(100)$ & \multirow[t]{2}{*}{1.0000} \\
\hline Yes (\%) & $13(7)$ & $13(7)$ & $0(0)$ & \\
\hline \multicolumn{5}{|l|}{ Leukocytosis } \\
\hline No (\%) & $102(53)$ & $95(52)$ & $7(58)$ & \multirow[t]{2}{*}{0.6801} \\
\hline Yes (\%) & $92(47)$ & $87(48)$ & $5(42)$ & \\
\hline \multicolumn{5}{|l|}{ Congenital vs Acquired } \\
\hline Acquired (\%) & $420(90)$ & $400(90)$ & $20(87)$ & \multirow[t]{2}{*}{0.7202} \\
\hline Congenital (\%) & $48(10)$ & $45(10)$ & $3(13)$ & \\
\hline \multicolumn{5}{|l|}{ Procedure Category } \\
\hline Gastrointestinal (\%) & $274(59)$ & $259(58)$ & $15(65)$ & \multirow[t]{6}{*}{0.7268} \\
\hline Genitourinary (\%) & $61(13)$ & $59(13)$ & $2(9)$ & \\
\hline Injury (\%) & $71(15)$ & $69(16)$ & $2(9)$ & \\
\hline Miscellaneous (\%) & $32(7)$ & $30(7)$ & $2(9)$ & \\
\hline Neoplasm (\%) & $19(4)$ & $18(4)$ & $1(4)$ & \\
\hline Surgical Infection (\%) & $11(2)$ & $10(2)$ & $1(4)$ & \\
\hline
\end{tabular}

Table 8 Multivariable Analysis for the Predictors of Prolonged Length of Stay $\geq 4$ Days, In-Hospital Mortality, and Readmission Within 90 Days

\begin{tabular}{|c|c|c|c|}
\hline Independent Predictor of Outcomes & OR $(95 \% \mathrm{Cl})$ & $p$-Value & Area Under the Curve \\
\hline Prolonged Length of Stay $\geq 4$ Days & & & $80 \%$ \\
\hline Gastrointestinal & $3.72(1.92,7.82)$ & 0.0002 & \\
\hline Injury & $3.13(1.43,7.27)$ & 0.005 & \\
\hline Surgical Infection & $12.12(3.00,62.64)$ & 0.0009 & \\
\hline Insurance & $0.41(0.18,0.94)$ & 0.0351 & \\
\hline In-Hospital Mortality & & & $98 \%$ \\
\hline Male Gender & $0.066(0.005,0.79)$ & 0.0321 & \\
\hline Older Age & $0.65(0.50,0.85)$ & 0.0016 & \\
\hline 90-Day Readmission & & & $74 \%$ \\
\hline Malaria & $4.04(1.28,12.74)$ & 0.0172 & \\
\hline
\end{tabular}


perioperative mortality, which is in contrast with previous studies [5, 7, 19, 34, 36]. However, it is important to note that only $10 \%$ of the patients in this study were female. Additional studies are needed to further investigate the relationship between gender and mortality in this region.

This study also identified several independent predictors of prolonged LOS, including gastrointestinal surgery, surgical injuries, surgical infections, and lack of insurance. It is to be expected that gastrointestinal surgery is associated with prolonged LOS, as many gastrointestinal procedures are major surgeries associated with an increased procedural complexity, increased risk of technical problems, longer surgical and anesthetic time, and immune deregulation resulting from the stress response to surgery or owing to impaired respiratory function in the postoperative period [37]. It is important to note that ERH does not have laparoscopy tools, so all procedures are performed using an open approach. In addition, surgical injuries can range from minor lacerations to complex polytraumas and surgical infections can range from localized abscesses to severe sepsis, with the more severe cases requiring extended admissions for medical management. However, it is possible that creating standardized management protocols can help to reduce the LOS in select cases. It is interesting to note that lack of insurance is associated with prolonged LOS. It is possible that lack of insurance may cause delayed presentation and therefore patients may present with more advanced disease, however it is also possible that patients without insurance are unable to pay their bills on time and therefore are kept in the hospital until their bills are paid. Additional studies need to be performed to further elucidate this association.

In comparing the results of this study to the literature, the average LOS for all pediatric surgical admissions in this study, 4.3 days, is similar to that reported by other studies [14,38]. The overall in-hospital mortality rate of $1.7 \%$ observed in this study was lower than the mortality rate of $12 \%$ reported in a systematic review of pediatric surgeries in LMICs in Africa [6]. It is possible that this could be explained in part by region-specific differences, as the mortality rate in this study is similar to another West African study looking at pediatric general surgical cases in Nigeria, suggesting that there may be some genetic and environmental differences [19]. However, it is more likely that the pediatric surgical patients operated on at ERH represent a less acute and complex patient population as the most complex patients were likely referred to hospitals with pediatric surgery specialists.

This study had several limitations. First, this was a retrospective study and therefore is subject to a lack of sufficient clinical details and is potentially vulnerable to confounding. Second, ERH does not have a pediatric surgical specialist and therefore this study has an inherent selection bias, as very young or complex pediatric surgical patients were often referred to the national hospital for management by pediatric surgeons as evidenced by the low number of congenital cases operated on at this facility. This could have contributed to the low number of infants and neonates in our study, which in turn may have limited the power of our analysis. Third, there were only 8 documented mortalities in this study, which could limit the power of our analysis. The mortality data collected was limited to in-hospital mortality, and as a result, mortality rates could have been underestimated. Some patients could have died at home and would not have been captured in the hospital records. In addition, all patients who were admitted to the surgical ward but did not undergo a procedure were excluded, therefore if a patient died prior to their scheduled procedure, their death would not be reflected on the calculated in-hospital mortality rate. Finally, there were only two documented surgical site infections (SSI) in this study cohort, which was not enough to allow for meaningful analysis. It is possible that some cases of SSI were missed if patients failed to present for follow up. Consequently, it is recommended that a prospective multicenter study with detailed follow-up be performed to increase the precision and external validity of the results.

\section{Conclusion}

In conclusion, this study revealed several areas for potential interventions to improve postoperative outcomes. First, malaria infection is a significant risk factor for readmission in the pediatric surgical population in rural Ghana. Preventing readmission in patients with malaria could lead to potential cost-savings and reductions in morbidity. Randomized control trials and prospective studies need to be completed to determine how to prevent readmission in patients with malaria. Improvements in the healthcare system to provide insurance to all patients and address other barriers to care may result in shorter hospital stays. Resources to provide laparoscopic equipment and training may reduce the length of stay for major gastrointestinal procedures. Improvements in the trauma system, including additional resources, additional training for staff, and a standardized multidisciplinary approach may result in improved management of injuries and reductions in the associated length of stay. Investment in workforce capacity building to train rural general surgeons, anesthetists and nurses to better address the specific perioperative needs of infants and young children, and ultimately training more pediatric surgeons to practice in regional and district hospitals, may result in lower pediatric surgery mortality rates in these settings. Future studies should also focus on further clarifying the association between female gender and mortality and the association between lack of insurance and prolonged length of stay in Ghana as well as to determine whether these associations are present in other regions. 


\section{Abbreviations}

LMICs: Low- and middle- income countries; SSI: Surgical site infections; ASA: American Society of Anesthesiologists; ERH: Eastern Regional Hospital; WBC: White Blood Cell count; LOS: Length of stay; HIV: Human immunodeficiency virus; Hgb: Hemoglobin; SD: Standard deviation; $\mathrm{Cl}$ : Confidence interval; OR: Odds ratio; AUC: Area under the operating characteristic curve; IQR: Interquartile range; MO: Month; YRS: Years; VS: Versus; USD: US dollars; GNI: Gross national income; GHS: Ghana cedi (currency)

\section{Acknowledgements}

The authors would like to thank the staff of Eastern Regional Hospital for their support throughout the data collection process. The authors would also like to acknowledge Michelle LaClair, MPH, a faculty member at Penn State College of Medicine, Department of Public Health Sciences for providing critical feedback on the manuscript.

\section{Authors' Contributions}

SP: Conceptualization, Methodology, Formal Analysis, Investigation, Data Curation, Writing- Original Draft, Visualization AES: Formal Analysis, Writing Review \& Editing LK: Conceptualization, Writing - Review \& Editing FAM: Investigation, Resources, Writing - Review \& Editing, Supervision RY: Resources, Project Administration ROA: Investigation, Resources TEA: Investigation, Resources EA: Investigation, Resources AT: Writing - Review \& Editing, Supervision JO: Conceptualization, Writing - Review \& Editing, Supervision PS: Conceptualization, Methodology, Formal Analysis, Writing Review \& Editing, Supervision, Project administration, Guarantor. All authors have read and approved this manuscript.

\section{Funding}

This research did not receive any specific grant from funding agencies in the public, commercial, or not-for-profit sectors.

\section{Availability of Data and Materials}

The datasets generated and analyzed during the current study are not publicly available to protect the privacy of the study participants but are available from the corresponding author on reasonable request.

\section{Ethics Approval and Consent to Participate}

The study protocol was reviewed and approved by the internal review board of Penn State Milton S. Hershey Medical Center and by the Eastern Regional Hospital for cultural appropriateness.

\section{Consent for Publication}

Not applicable.

\section{Competing Interests}

The authors declare no conflict of interest.

\section{Author details}

${ }^{1}$ Penn State University College of Medicine, 500 University Drive, Hershey, PA 17033, USA. ${ }^{2}$ Eastern Regional Hospital, P.O. Box 201, Koforidua, Ghana.

Received: 18 January 2020 Accepted: 8 September 2020 Published online: 22 September 2020

\section{References}

1. BM Biccard TE Madiba HL Kluyts DM Munlemvo FD Madzimbamuto A Basenero et al 2018 Perioperative patient outcomes in the African Surgical Outcomes Study: a 7-day prospective observational cohort study Lancet 391 15891598 https://doi.org/10.1016/S0140-6736(18)30001-1.

2. JG Meara AJM Leather L Hagander BC Alkire N Alonso EA Ameh et al 2015 Global Surgery 2030: Evidence and solutions for achieving health, welfare, and economic development Lancet 386569624 https://doi.org/10.1016/ S0140-6736(15)60160-X.

3. Kaneda Toshiko, Greenbaum C, Patierno K. 2018 World Population Data Sheet. Population Reference Bureau. 2018.

4. EK Butler TM Tran N Nagarajan J Canner AT Fuller A Kushner et al 2017 Epidemiology of pediatric surgical needs in low-income countries PLoS One 12 e0170968 https://doi.org/10.1371/journal.pone.0170968.
5. SW Bickler H Rode 2002 Surgical services for children in developing countries Bull World Health Organ 80829835 https://doi.org/10.1590/ s0042-96862002001000013.

6. MH Livingston J Dcruz J Pemberton D Ozgediz D Poenaru 2015 Mortality of pediatric surgical conditions in low and middle income countries in Africa J Pediatr Surg 50760764 https://doi.org/10.1016/j.jpedsurg.2015.02.031.

7. W Pignaton JRC Braz PS Kusano MP Módolo LR Carvalho MG de Braz et al 2016 Perioperative and anesthesia-related mortality: An 8-year observational survey from a tertiary teaching hospital Medicine 9516 https://doi.org/10. 1097/MD.0000000000002208.

8. D Bainbridge J Martin M Arango D Cheng 2012 Perioperative and anaesthetic-related mortality in developed and developing countries: A systematic review and meta-analysis Lancet 38010751081 https://doi.org/ 10.1016/S0140-6736(12)60990-8.

9. D Catré MF Lopes JS Viana AS Cabrita 2015 Perioperative morbidity and mortality in the first year of life: a systematic review (1997-2012) Rev Bras Anestesiol 65384394 https://doi.org/10.1016/j.bjane.2013.03.025.

10. KM Chu Nathan Ford Miguel Trelles Operative Mortality in Resource-Limited Settings: The Experience of Medecins Sans Frotieres in 13 Countries Arch Surg 20101457215 https://doi.org/10.1001/archsurg.2010.137.

11. RP Flick Juraj Sprung TE Harrison SJ Gleich DR Schroeder AC Hanson et al Perioperative cardiac arrests in children between 1988 and 2005 at a tertiary referral center: A study of 92,881 patients Anesthesiology 200710622637 https://doi.org/10.1097/00000542-200702000-00009.

12. BF van der Griend NA Lister, IM McKenzie, Nick Martin, PG Ragg, SJ Sheppard et al Postoperative Mortality in Children After 101,995 Anesthetics at a Tertiary Pediatric Hospital Anesth Analg 201111214407 https://doi. org/10.1213/ANE.0b013e318213be52.

13. SW Bickler J Kyambi H Rode Pediatric surgery in sub-Saharan Africa Pediatr Surg Int 2001174427 https://doi.org/10.1007/s003830000516.

14. JS Karpelowsky HJ Zar G Bogerijen N van Graaf AJW van der Millar 2011 Predictors of postoperative complications in HIV-infected children undergoing surgery J Pediatr Surg 46674678 https://doi.org/10.1016/j. jpedsurg.2010.11.026.

15. JS Karpelowsky AJW Millar N Graaf G van der Bogerijen HJ van Zar Comparison of in-hospital morbidity and mortality in HIV-infected and uninfected children after surgery Pediatr Surg Int 281007 https://doi.org/10. 1007/s00383-012-3163-x.

16. D Soltanifar B Carvalho P Sultan 2015 Perioperative considerations of the patient with malaria Can J Anesth 62304318 https://doi.org/10.1007/ s12630-014-0286-7.

17. M Pilkington M Situma A Winthrop D Poenaru 2018 Quantifying delays and self-identified barriers to timely access to pediatric surgery at Mbarara Regional Referral Hospital Uganda J Pediatr Surg 53 https://doi.org/10.1016/ j.jpedsurg.2018.02.045.

18. RO Ugwu PE Okoro 2013 Pattern, outcome and challenges of neonatal surgical cases in a tertiary teaching hospital Afr J Paediatr Surg10 226230 https://doi.org/10.4103/0189-6725.120886.

19. AOlusegun Talabi OAdedapo Sowande ATaiwo Adenekan Olusanya Adejuyigbe CChijioke Adumah AObasi Igwe A 10-year retrospective review of perioperative mortality in pediatric general surgery at Ile-Ife Hospital, Nigeria J Pediatr Surg 20195320726 https://doi.org/10.1016/j.jpedsurg. 2018.03.005.

20. SA McClave HL Snider DA Spain 1999 Preoperative Issues in Clinical Nutrition Chest 115 64S 70S https://doi.org/10.1378/chest.115.suppl.

21. Stone M. Cross-validatory choice and assessment of statistical predictions. J Roy Stat Soc: Ser B (Methodol). 1974;36:111-33.

22. Hosmer D, Lemeshow S, Sturdivant RX. Area under the operating characteristic curve. Appl Logistic Regression. 2013;3:173-81.

23. GL Roark 2019 Retrospective Comparison of 2 Management Strategies for Perioperative Malaria Episodes in Pediatric Patients in a Limited-Resource Setting Anesth Analg 129515519 https://doi.org/10.1213/ANE. 0000000000004186.

24. N Eipe 2004 Malaria and postoperative fever 3] Acta Anaesthesiol Scand 48 1217 https://doi.org/10.1111/j.1399-6576.2004.00494.x.

25. H Husum T Heger M Sundet 2002 Postinjury malaria: a study of trauma victims in cambodia J Trauma 52259266 https://doi.org/10.1097/00005373200202000-00010.

26. M Sundet T Heger H Husum 2004 Post-injury malaria: A risk factor for wound infection and protracted recovery Tropical Med Int Health 9238242 https://doi.org/10.1046/j.1365-3156.2003.01190.x. 
27. Heger T, Han SC, van Heng Y, Sunder M, Larsen S, Husurn H. Early diagnosis and treatment of falciparum malaria in cambodian trauma patients. Southeast Asian J Trop Med Public Health. 2009;40:1135-47. .

28. Heger $T$, Sundet $M$, Yang VH, Rattana $Y$, Husum H. Postinjury malaria: Experiences of doctors in Battambang Province, Cambodia. Southeast Asian J Trop Med Public Health. 2005;36:811-5. .

29. C Afoakwah X Deng I Onur 2018 Malaria infection among children underfive: The use of large-scale interventions in Ghana BMC Public Health 181 14 https://doi.org/10.1186/s12889-018-5428-3.

30. GE Grau PC Piguet P Vassalli P-H Lambert 1989 Tumor-Necrosis Factor and other Cytokines in Cerebral Malaria: Experimental and Clinical Data Immunol Rev 1124970 https://doi.org/10.1111/j.1600-065X.1989.tb00552.x.

31. World Development Indicators. The World Bank DataBank 2019. https: Icrwww.databank.worldbank.org/data/reports.aspx?source=2\&series=SI.POV. GINI\&country=GHA Accessed Feb 42019.

32. Cooke E, Hague S, McJay A. The Ghana Poverty and Inequality Report: Using the 6th Ghana Living Standards Survey. UNICEF 2016. https://www.unicef. org/ghana/Ghana_Poverty_and_Inequality_Analysis_FINAL_Match_2016(1). pdf Accessed Feb 42019

33. MM Cohen CB Cameron PG Duncan 1990 Pediatric anesthesia morbidity and mortality in the perioperative period Anesth Analg $70160167 \mathrm{https} / /$ doi.org/10.1213/00000539-199002000-00005.

34. LP Gonzalez JRC Braz MP Módolo LR Carvalho de NSP Módolo LG Braz 2014 Pediatric perioperative cardiac arrest and mortality: A study from a tertiary teaching hospital Pediatr Crit Care Med 15878884 https://doi.org/10.1097/ PCC 0000000000000248 .

35. Upperman J, Ford H. Sepsis and Related Considerations. In: Grosfeld J, O'Neil J, Fonkalsrud E, Coran A, editors. Pediatric Surgery. 6th ed. Philadelphia: Mosby Elsevier; 2006. p. 156-77.

36. MC Newland SJ Ellis CA Lydiatt KR Peters JH Tinker DJ Romberger et al 2002 Anesthestic-related Cardiac Arrest and Its Mortality Anesthesiology 97 108115 https://doi.org/10.1097/00000542-200207000-00016.

37. M McHoney S Eaton A Pierro 2009 Metabolic Response to Surgery in Infants and Children Eur J Pediatr Surg 19275285 https://doi.org/10.1055/s-00291241192.

38. T Firomsa M Teferra A Tadesse 2018 Pediatric Surgical Admissions... Trends and Outcomes of Emergency Pediatric Surgical Admissions from a Tertiary Hospital in Ethiopia Ethiop J Health Sci 28251258 https://doi.org/10.4314/ ejhs.v28i3.2.

\section{Publisher's Note}

Springer Nature remains neutral with regard to jurisdictional claims in published maps and institutional affiliations.

Ready to submit your research? Choose BMC and benefit from:

- fast, convenient online submission

- thorough peer review by experienced researchers in your field

- rapid publication on acceptance

- support for research data, including large and complex data types

- gold Open Access which fosters wider collaboration and increased citations

- maximum visibility for your research: over $100 \mathrm{M}$ website views per year

At $\mathrm{BMC}$, research is always in progress.

Learn more biomedcentral.com/submissions 